\title{
Optimal Capacity Determination For Electrical Distribution Transformers Based On IEC 60076-7 And Practical Load Data
}

\author{
Keyvan Farahzad ${ }^{\mathrm{a}}$, Aliakbar Shahbahrami ${ }^{\mathrm{a}}$, Mani Ashouri ${ }^{\mathrm{b}}$ \\ ${ }^{a}$ Iranian Northern DSO, Nowshahr, Iran \\ ${ }^{b} \mathrm{PhD}$ Student at Aalborg University, Aalborg, Denmark
}

Received: 24 September 2019; Accepted: 15 October 2019; Published: 08 February 2020

\begin{abstract}
Optimal installation of electrical distribution transformers has always been a challenging task for distribution operator (DSO)s due to load variations, particularly for seasonal loads. Depending on the quality of distribution systems in different regions and countries, a considerable number of installed transformers may be oversized or have capacity lower than critical standard. In this study, IEC 60076-7 is used to calculate the temperature limitations for distribution transformer capacities and determine optimal transformer capacity for an electrical distribution substation based on the critical values and limitations given in the standard. A data logger is installed on the substation and the load data is recorded for one year. Additionally, the impact of different parameters like ambient temperature is investigated for optimal determination of transformer capacity.
\end{abstract}

Index Terms: Distribution Transformer, IEC 60076-7, Capacity Determination, DSO, Practical Load.

(C) 2020 Published by MECS Publisher. Selection and/or peer review under responsibility of the Research Association of Mode rn Education and Computer Science

* Corresponding author.

E-mail address: 


\section{Introduction}

Electrical distribution systems are of significant importance in the field of power systems and energy due to being the final stage in delivering electrical power to the consumers [1]. In both traditional distribution systems and grids including renewable generation, optimal implementation of the equipment and their operation is one of the important and challenging tasks [2-4]. The distribution system operator (DSO)s always try to keep the electrical distribution system in an optimal shape trying to keep a trade-off between the costs and the quality of the grid [5]. Accordingly, other than different optimization studies in electrical power systems [6-8], there are additional studies like optimal capacity determination for electrical distribution transformers, which helps the DSOs to have a more cost saving grid, while keeping the distribution system in a reliable and high quality condition [9].

In seasonal and rural regions, the load in summer seasons is significantly higher than the other periods of the year [10]. Additionally, different parameters like variable ambient temperature have a considerable impact on the needed capacity of electrical distribution transformers. Moreover, depending on the quality of distribution systems in different regions and countries, a considerable number of installed transformers may be oversized or have capacity lower than critical standard. Thereupon, different parameters and limitations should be considered to determine the optimal capacity needed for electrical distribution transformers. IEC 60076-7 is published as a loading guide for mineral-oil-immersed transformers [11]. According to this study, the hotspot temperature of the transformers is calculated for different load intervals and various limitations and thresholds introduced, which can be used to determine the optimal capacity needed for a specific distribution substation. Although several discussion remains in protection and dynamics of the transformers and the system [12], and also the interactions between the distribution system and the HVAC or HVDC grids [13] and the transients injected to the distribution system from the upper grid, this study only focuses on steady-state analysis of the distribution system, doing steady state calculations for optimal capacity determination of distribution transformers [14-15].

A practical electrical distribution substation is considered in this study and a data logger is installed in the feeder to accurately record yearly load variations. Different standard distribution capacities are used to calculate the hotspot temperature and determine the minimum capacity, which does not exceed the limitation based on the IEC 60076-7 standard. Additionally, the impact of different parameters like the ambient temperature on the optimal determined capacity is investigated and the sensitivity analysis is done for some of the parameters and constants used in the calculation process.

The novelty of this paper is to have optimal distribution transformer installations based on IEC 60076-7 instead of installing transformer capacities based on experiment, which leads oversized capacity installations and non-optimal electrical distribution system. According to authors' knowledge, this method of capacity distribution based on thermal limitations of IEC 60076-7 was not investigated in literature work.

The remainder of this paper is organized as follows: Section 2 gives basic definitions and the required explanations. Section 3 explains the calculation process for transformer hotspot temperature based on IEC-60076-7 standard. The whole process and the corresponding constants are given in section 4. Section 5 give the experimental results and discussions are given in section 6 . Finally, section 7 concludes the study. 


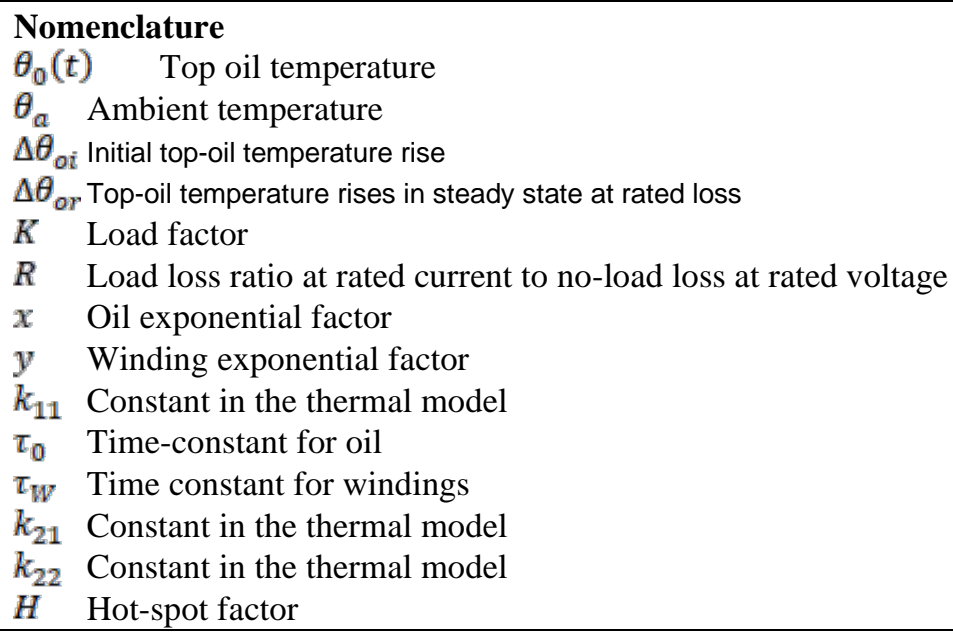

\section{Basic definitions based on IEC 60076-7}

In this section, the basic definitions are given based on IEC 60076-7, which are needed for further analysis of the distribution transformers. Each of the categories has specific constant and parameter values, which are different than other categories.

\section{1 Types of transformers}

According to IEC 60076-7, the transformers are categorized into 3 groups based on their size, namely large, medium and small transformers [11]. The definition for the small transformers is a power transformer without attached radiators, external tubes or coolers. This definition is not related to the rating and any transformer with this specification is considered as small transformer. The distribution transformers are also included in this category. Accordingly, the constant and parameter values for the category of small transformers are used in the formulations and calculations.

\subsection{Types of cyclic loadings}

According to IEC 60076-7, three cyclic loadings are defined as normal cyclic loading, short-term emergency loading, and long-term emergency loading. According to the standard, loading that a higher ambient temperature with the thermal ageing rate same as the rated load at normal ambient temperature is defined as a normal cyclic loading [11]. The loading in this study is categorized in the normal cyclic loading.

\section{Calculation of transformer hotspot temperature}

In this section, the calculation method for distribution transformer hotspot temperature is explained. According to IEC 60076-7 there are different methods for determining the hotspot temperature like direct measurement, exponential equations and difference equation method. In this study, exponential equations method is used to determine the hotspot temperature.

Transformer top-oil temperature increase and decrease corresponding to the load factor $K$ is calculated using eq.s (1-2)[11]: 


$$
\begin{aligned}
& \theta_{0}(t)=\theta_{a}+\Delta \theta_{o i}+\left\{\Delta \theta_{o r} \times\left[\frac{1+R \times K^{2}}{1+R}\right]^{x}-\Delta \theta_{o i}\right\} \times\left(1-e^{\frac{-t}{k_{11} \times \tau_{0}}}\right) \\
& \theta_{0}(t)=\theta_{a}+\Delta \theta_{o r} \times\left[\frac{1+R \times K^{2}}{1+R}\right]^{x}+\left\{\Delta \theta_{o i}-\Delta \theta_{o r} \times\left[\frac{1+R \times K^{2}}{1+R}\right]^{x}\right\} \times e^{\frac{-t}{k_{11} \times \tau_{0}}}
\end{aligned}
$$

Where, $\theta_{0}(t)$ is the top-oil temperature, $\theta_{a}$ is the ambient temperature, $\Delta \theta_{o i}$ is initial top-oil temperature rise, $\Delta \theta_{o r}$ is the steady-state temperature rise, $K$ is the load factor, $R$ is the ratio of load losses at rated current to no-load losses at rated voltage, $k_{11}$ is temperature model constant and $\tau_{0}$ is the oil time constant.

In a specific load factor $K$ the hotspot to the top-oil gradient increase is obtained using[11]:

$$
\Delta \theta_{h}(t)=\Delta \theta_{h 1}(t)-\Delta \theta_{h 2}(t)
$$

Where, $\Delta \theta_{h 1}(t)$ and $\Delta \theta_{h 2}(t)$ are gradients and will be determined using [11]:

$$
\begin{gathered}
\Delta \theta_{h 1}(t)=\Delta \theta_{h 1 i}+\left\{k_{21} H g_{r} K^{y}-\Delta \theta_{h 1 i}\right\} \times\left(1-e^{\frac{-t}{k_{22} \times r_{W}}}\right) \\
\Delta \theta_{h 2}(t)=\Delta \theta_{h 2 i}+\left\{\left(k_{21}-1\right) H g_{r} K^{y}-\Delta \theta_{h 2 i}\right\} \times\left(1-e^{\frac{-t \times k_{22}}{\tau_{0}}}\right)
\end{gathered}
$$

In another hand, in the hotspot to the top-oil gradient decrease, equations (4-5) will be changed to[11]:

$$
\begin{aligned}
& \left.\Delta \theta_{h 1}(t)=k_{21} H g_{r} K^{y}+\left\{\Delta \theta_{h 1 i}-k_{21} H g_{r} K^{y}\right\} \times e^{\frac{-t}{k_{22} \times \tau_{W}}}\right) \\
& \left.\Delta \theta_{h 2}(t)=\left(k_{21}-1\right) H g_{r} K^{y}+\left\{\Delta \theta_{h 2 i}-\left(k_{21}-1\right) H g_{r} K^{y}\right\} \times e^{\frac{-t \times k_{22}}{\tau_{0}}}\right)
\end{aligned}
$$

Finally, the hotspot temperature is obtained using [11]:

$$
\theta_{h}(t)=\theta_{0}(t)+\Delta \theta_{h}(t)
$$

\section{The proposed procedure for Optimal capacity determination based on exponential equations method}

The process of using IEC 60076-7 for determining the optimal capacity is explained in this section. In the first step, the yearly load data for the distribution transformer is imported to MATLAB and the load factor is calculated for each time interval. According to the current limitation from IEC 60076-7, the load must not exceed 1.5 multiples of the transformer rated load. This limitation is the first step of checking the capacities. Then the next step is calculated. Then, Transformer top-oil temperature increase and decrease is calculated using (1-2). In sequence, hotspot to the top-oil gradient increase and decrease is calculated using (3-7). Then, the hotspot temperature in the first interval is calculated using (8). This procedure is repeated for all the time intervals. In this study, standard transformer capacities of 25, 50, 100, 125, 160, 200, 250, 315 and 630 KVA are considered as the steps of the algorithm. Accordingly, the explained procedure is calculated for the 
minimum capacity first. If the limitations are exceeded, the calculations will be repeated for the upper interval, until the optimal capacity is determined. Fig. 1 depicts the flowchart of the whole process.

\section{Experimental results using practical data}

In this study, a data logger is installed to measure the yearly practical load of a distribution transformer installed on a $20 \mathrm{KV}$ feeder, in the northern region of Iran, named Darvishabad station. The yearly peak load for this transformer was 140.5 KVA, which happened at 25 July 2018. Fig. 2 and 3 depict the yearly load curve, and the load percentage compared to time, for Darvishabad transformer, respectively. According to the Fig. 2, it is clearly obvious that the transformer is installed in a rural area and has seasonal load type, which has high load factor in summer season and significantly small load factor in the rest of the year.

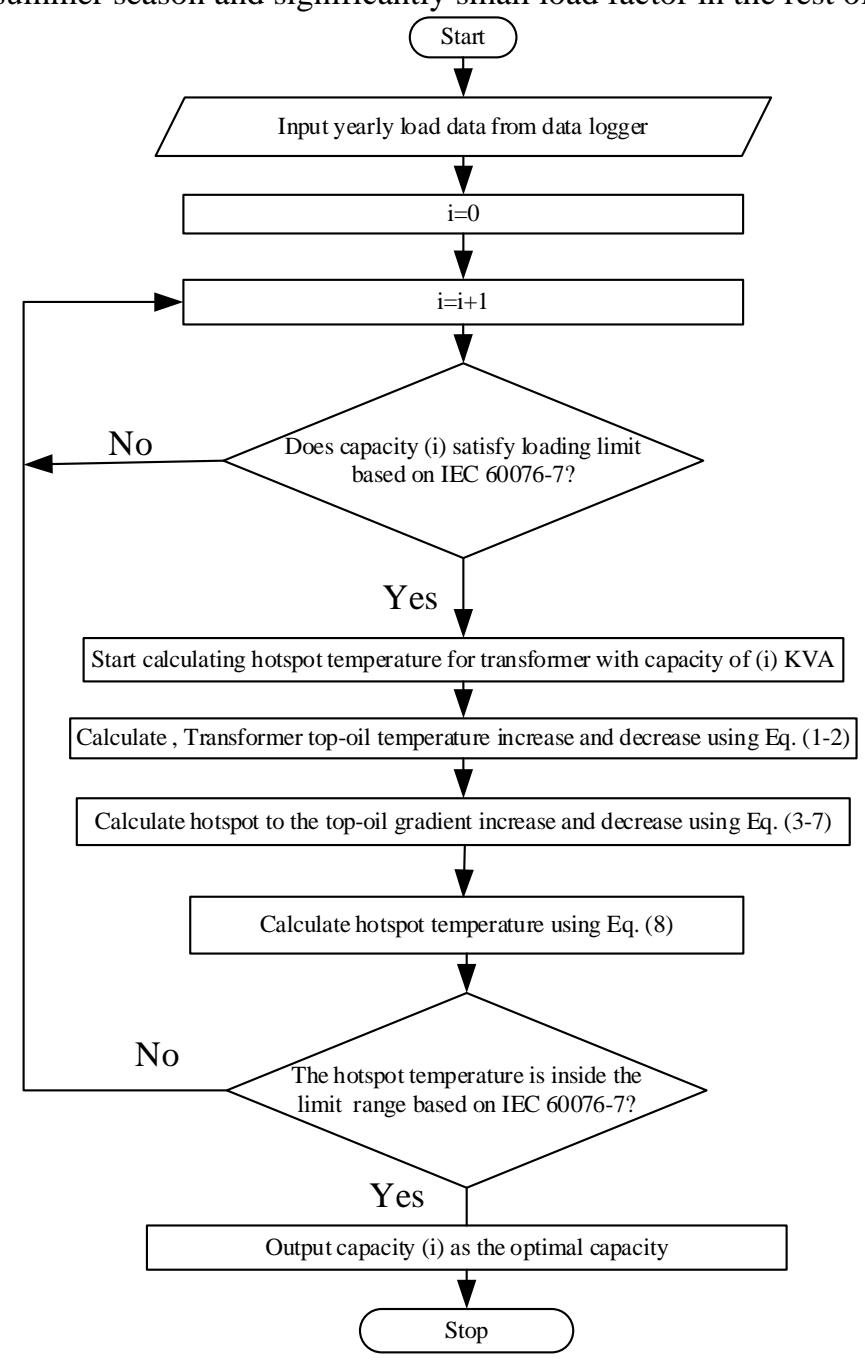

Fig. 1: Yearly load percentage time diagram for Darvishabad station transformer 


\subsection{Main simulation results}

According to the current limitation from IEC 60076-7, the load must not exceed 1.5 multiples of the transformer rated load. Accordingly, with the peak load of 140.5 KVA, 25 and 50 KVA transformers are not proper choices for the measured load.

The yearly load curve is imported to MATLAB and the algorithm is applied to the load curve based on the flowchart given in Fig. 1. Table 1 gives the parameter values used in this study. According to the yearly load curve given in Fig. 2, the hotspot temperature of different transformer capacities is given in Fig. 4.

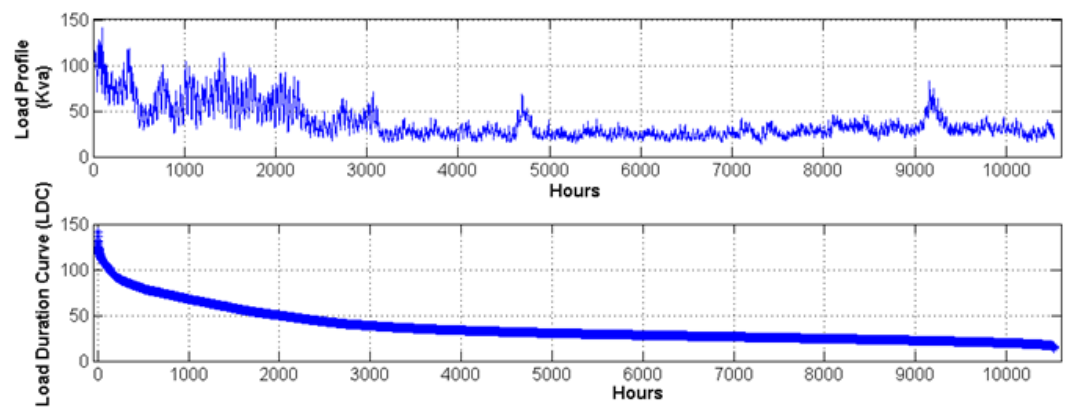

Fig. 2: Yearly load percentage time diagram for Darvishabad transformer

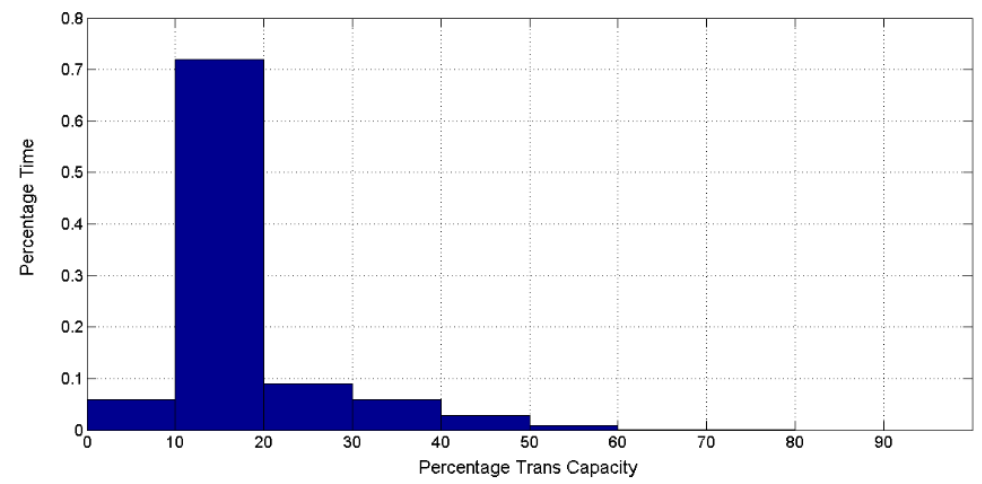

Fig. 3: Yearly load curve for Darvishabad transformer 

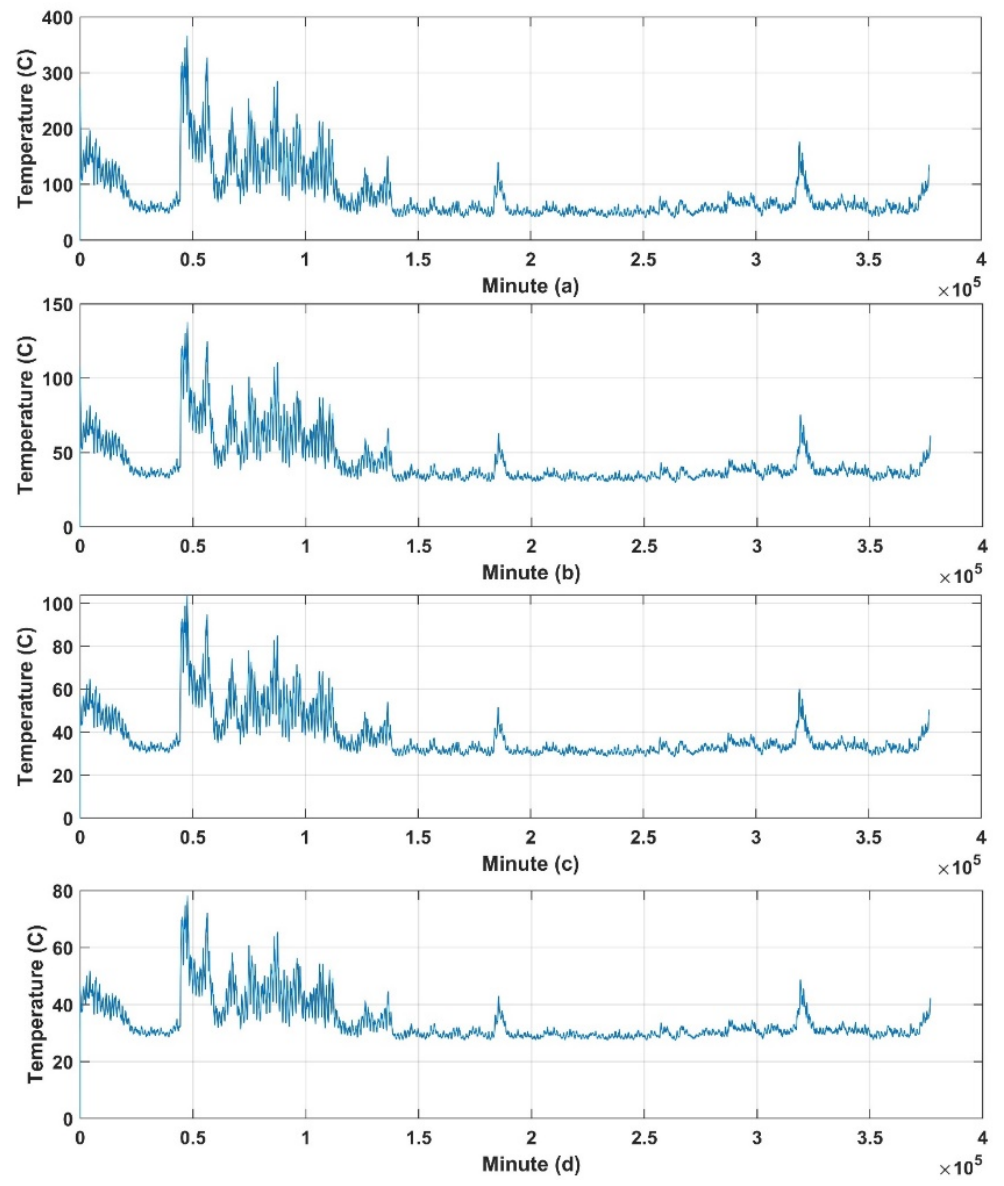

Fig. 4: Calculated yearly hotspot temperature. (a): 50 KVA transformer, (b): 100 KVA transformer, (c): 125 KVA transformer, (d): 150 KVA transformer.

Table 1. Parameter values used in this study

\begin{tabular}{clcl}
\hline Parameter & Value & Parameter & Value \\
\hline$H$ & 1.1 & $k_{11}$ & 1.0 \\
$\mathrm{R}$ & 5.0 & $k_{21}$ & 1.0 \\
$g_{r}$ & 14.5 & $k_{22}$ & 2.0 \\
$\tau_{W}$ & 4.0 & $x$ & 0.8 \\
$\tau_{0}$ & 180 & $y$ & 1.6 \\
\hline
\end{tabular}

According to Fig. 4 (a) and Fig 4 (b), the hotspot temperature has exceeded from the standard limit of $120{ }^{\circ} \mathrm{C}$, which is given in the IEC 60076-7 standard. Accordingly, the capacities of 50 and $100 \mathrm{KVA}$ cannot be the optimal capacities for this station. Fig. 4 (c) shows that the yearly hotspot temperature has not exceeded the limit of $120^{\circ} \mathrm{C}$. Accordingly, the capacity of $125 \mathrm{KVA}$ is obtained as the optimal capacity based on IEC 60076-7. 


\subsection{Sensitivity Analysis to the ambient temperature}

In this section, the hotspot temperature of the transformer is calculated in different ambient temperatures. The ambient temperatures varies from $25{ }^{\circ} \mathrm{C}$ to $60^{\circ} \mathrm{C}$. Fig. 5 depicts the hotspot temperature of a $125 \mathrm{KVA}$ capacity distribution transformer installed on Darvishabad station. Considering the optimal capacity of $125^{\circ} \mathrm{C}$, which was resulted in section 5, Table 2 shows the optimal capacity in different ambient temperatures. According to the Table 2 and Fig. 4, for the temperatures equal or higher than $40{ }^{\circ} \mathrm{C}, 125 \mathrm{KVA}$ is not the optimal capacity and the upper standard value, namely $160 \mathrm{KVA}$ transformer will be the optimal distribution capacity for Darvishabad station.

Table 2. Optimal transformer capacity based on the ambient temperature

\begin{tabular}{ccccccccc}
\hline Ambient temperature $\left({ }^{\circ} \mathrm{C}\right)$ & 25 & 30 & 35 & 40 & 45 & 50 & 55 & 60 \\
\hline Optimal capacity 25 (KVA) & 125 & 125 & 125 & 160 & 160 & 160 & 160 & 160 \\
\hline
\end{tabular}
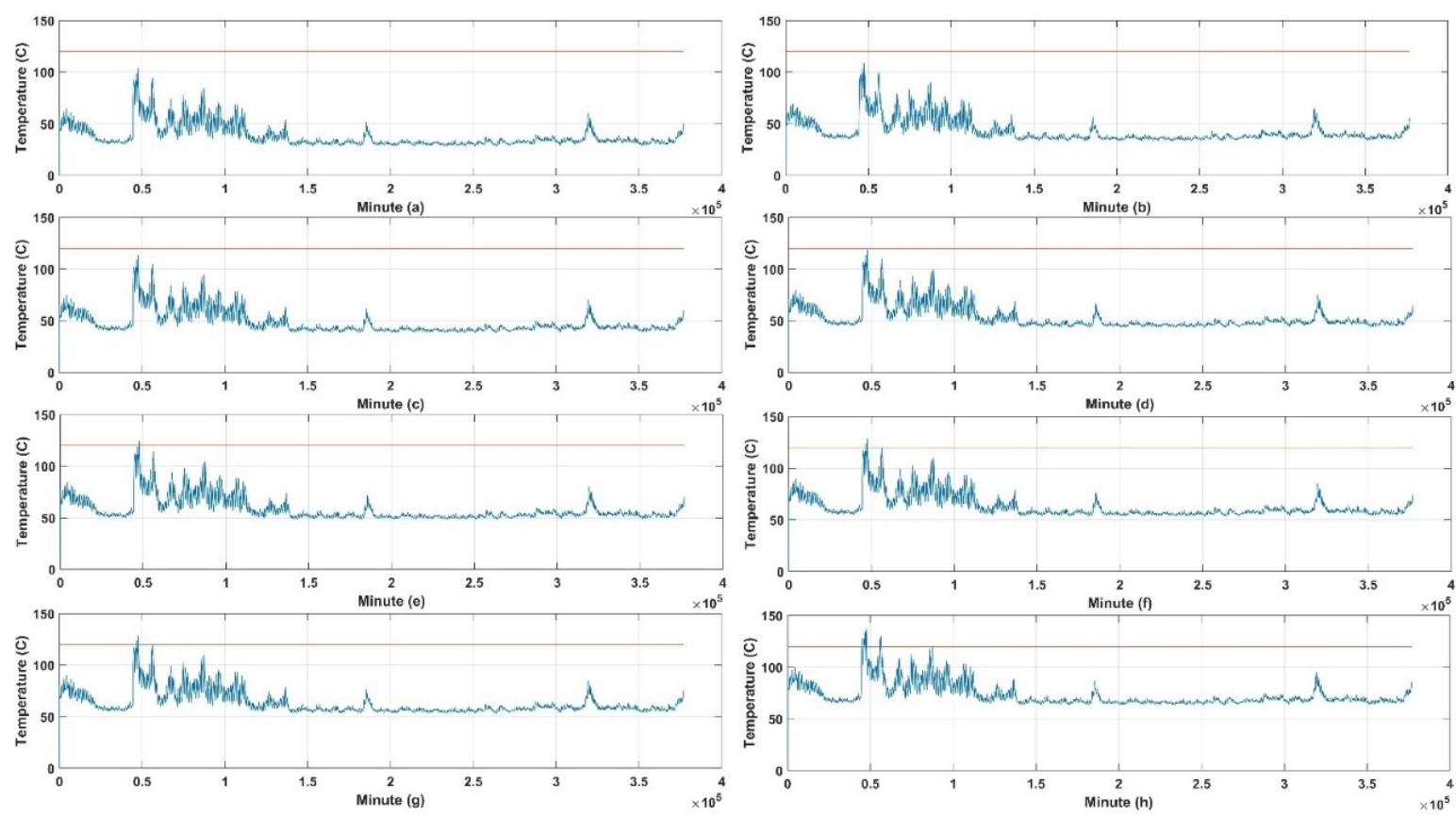

Fig. 5: Hotspot temperature in different ambient temperatures for $125 \mathrm{KVA}$ transformer. (a): $25^{\circ} \mathrm{C},(\mathrm{b}): 30^{\circ} \mathrm{C},(\mathrm{c}): 35^{\circ} \mathrm{C},(\mathrm{d}): 40{ }^{\circ} \mathrm{C},(\mathrm{e})$ : $45^{\circ} \mathrm{C}$, (f): $50{ }^{\circ} \mathrm{C},(\mathrm{g}): 55^{\circ} \mathrm{C},(\mathrm{h}): 60^{\circ} \mathrm{C}$

\section{Discussion}

According to the results given in section 6, with increasing the ambient temperature, the optimal capacity is changed one step above. It should be mentioned that in some case, where the optimal capacity is closer to the yearly peak load, it may stay constant with increase in the ambient temperature. In this study, the yearly ambient temperature is considered to be a constant value. According to IEC 60076-7, the definition of the 
ambient temperature is the monthly average temperature of the hottest month. However, to have more accurate results, time-varying ambient temperature can be used. Another important thing to consider is that all of the calculations given in this paper, are done for brand new transformers. For the transformers, which had been commissioned years before and are online for a long period, ageing factors must be considered and correction parameters should be defined. Additionally, there other parameters like outdoor ambient conditions, which may affect the optimal capacity results. Due to lack of a straightforward method for modeling these conditions, they are neglected in this study.

\section{Conclusion}

In this paper, optimal distribution transformer capacity is determined based on IEC 60076-7. The resulted capacities can help keeping the distribution grid in the most optimum condition, removing the redundant installed capacities in the grid. This is achieved by calculating the yearly hotspot temperature of distribution transformers installed in target substations. The yearly load of the specific transformers, are measured using data logger during one full year, and the practical data is imported to the optimization algorithm, which is designed based on IEC 60076-7 equations. The temperature limits have also been taken from IEC 60076-7 to check the validity of different capacities. A sensitivity analysis is done to calculate optimal values in different ambient conditions, It is resulted that in higher ambient conditions, the optimal capacities will change to the upper standard level. Further works, consist of defining time-variable ambient temperature to have more accurate results. The ageing factors must be designed to extend this study to the aged transformers, which are online for a long period.

\section{References}

[1] S. Wang, "Study on the selection method of economical capacity for MV transformers," in 2012 China International Conference on Electricity Distribution, 2012, pp. 1-5.

[2] A. Izanlo, S. A. Gholamian, and M. V. Kazemi, "Using of four-switch three-phase converter in the structure DPC of DFIG under unbalanced grid voltage condition,” Electr. Eng., vol. 100, no. 3, pp. 1925-1938, 2018.

[3] A. Izanlo, S. Asghar Gholamian, and M. V. Kazemi, "Comparative study between two sensorless methods for direct power control of doubly fed induction generator,” Rev. Roum. des Sci. Tech. Ser. Electrotech. Energ., vol. 62, no. 4, pp. 358-364, 2017.

[4] M. Verij Kazemi, S. A. Gholamian, and J. Sadati, “Adaptive frequency control with variable speed wind turbines using data-driven method,” J. Renew. Sustain. Energy, vol. 11, no. 4, p. 043305, Jul. 2019.

[5] S. N. G. Gourisetti, H. Kirkham, and D. Sivaraman, "A review of transformer aging and control strategies,” in 2017 North American Power Symposium (NAPS), 2017, pp. 1-6.

[6] M. Ashouri and S. Mehdi Hosseini, "Application of Krill Herd and Water Cycle Algorithms on Dynamic Economic Load Dispatch Problem,” Int. J. Inf. Eng. Electron. Bus., vol. 6, no. 4, pp. 12-19, Aug. 2014.

[7] Y. Najafi Sarem, J. Poshtan, M. Ghomi, and M. Poshtan, “Synchronous generator parameters estimation,” in 2007 International Conference on Intelligent and Advanced Systems, 2007, pp. 870-875.

[8] B. Shakerighadi, A. Anvari-Moghaddam, E. Ebrahimzadeh, F. Blaabjerg, and C. L. Bak, “A Hierarchical Game Theoretical Approach for Energy Management of Electric Vehicles and Charging Stations in Smart Grids,” IEEE Access, vol. 6, pp. 67223-67234, 2018. 
[9] S. Bahramara and F. G. Mohammadi, "Optimal sizing of distribution network transformers considering power quality problems of non-linear loads,” CIRED - Open Access Proc. J., vol. 2017, no. 1, pp. 2471-2475, 2017.

[10] Z. Q. Liang and Y. Q. Yang, "The Energy Saving Research of the On-Load Capacity Regulating Transformer in Practical Applications,” Adv. Mater. Res., vol. 962-965, pp. 1504-1508, Jun. 2014.

[11] C. International and E. Commission, "IEC 60076-7 International Standard- Loading guide for mineral-oil-immersed power transformers," 2018.

[12] M. Ashouri, H. Khazraj, F. F. da Silva, and C. Leth Bak, "Protection of Multi-Terminal VSC-HVDC Grids Based on the Response of the First Carrier Frequency Harmonic Current,” in 2018 53rd International Universities Power Engineering Conference (UPEC), 2018, pp. 1-5.

[13] M. Ashouri, C. L. Bak, and F. Faria Da Silva, "A review of the protection algorithms for multi-terminal VCD-HVDC grids,” in 2018 IEEE International Conference on Industrial Technology (ICIT), 2018, pp. 1673-1678.

[14] Z. Y. Zheng et al., "A New Capacity Inspection Method for Distribution Transformer based on Big Data,” in 2018 China International Conference on Electricity Distribution (CICED), 2018, pp. 38-41.

[15] H. Jun, H. Junhui, G. Sanrong, T. Jian, and L. Hu, “Optimization and modeling of power supply capability in distribution system based on analyzing interconnections among main transformer,” in 2016 China International Conference on Electricity Distribution (CICED), 2016, pp. 1-5. 


\section{Authors' Profiles}

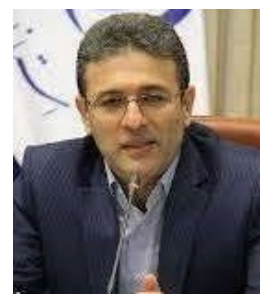

Keyvan Farahzad received his B.Sc. and M.Sc. from Tehran Polytechnic University in electrical engineering, Tehran, Iran. He is currently the CEO of Iranian northern DSO. He has more than 20 years of experience in electrical distribution system operation and planning. His current research interests are application of signal processing in electrical distribution systems, Optimal transformer allocation in distribution systems abd medium voltage DC distribution system protection and control.

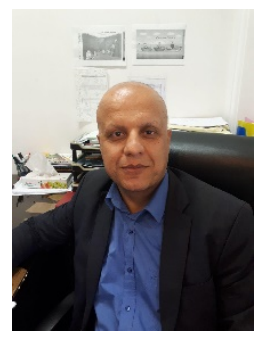

Aliakbar Shahbahrami received his B.Sc. from Tehran Polytechnic University in electrical engineering and received his Ms.C. from Qazvin University. He is currently the head of the R\&D section in Iranian northern DSO. His research interests are electrical distribution system planning, optimal distribution system design, Seasonal load analysis and data science.

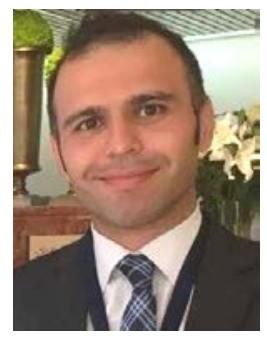

Mani Ashouri received his B.Sc. and M.Sc. from Babol University of technology, Iran. He is currently a Ph.D. student in the Department of Energy Technology, Aalborg University, Denmark. He had been working as HVAC protection and relay test engineer during 2011-2017 in Iranian northern TSO. His main research interests are protection and control of multi-terminal VSC-HVDC and HVAC systems, Electromagnetic transients in electrical power systems and high voltage cables, power electronic converters used for HVDC transmission and signal processing methods for power system fault analysis.

How to cite this paper: Keyvan Farahzad, Aliakbar Shahbahrami, Mani Ashouri. "Optimal Capacity Determination For Electrical Distribution Transformers Based On IEC 60076-7 And Practical Load Data", International Journal of Engineering and Manufacturing(IJEM), Vol.10, No.1, pp.1-11, 2020. DOI: 10.5815/ijem.2020.01.01 